\title{
Synthesis of novel organocatalyzed phenoxazine for free metal atom transfer radical polymerization
}

\author{
Thu Hoang Vo ${ }^{1,2}$, Huong Thi Le ${ }^{1,3}$, Tien Anh Nguyen ${ }^{3}$, Nhu Quang Ho1, Thang Van Le ${ }^{2,4}$, Dat Hung Tran1, \\ Thuy Thu Truong ${ }^{2}$ and Ha Tran Nguyen ${ }^{1,2 *}$ (D)
}

\begin{abstract}
${ }^{1}$ National Key Laboratory of Polymer and Composite Materials, Ho Chi Minh city University of Technology, Vietnam National University - VNU-HCM, Ho Chi Minh City, Vietnam

${ }^{2}$ Faculty of Materials Technology, Ho Chi Minh City University of Technology, Vietnam National University, Ho Chi Minh City, Vietnam

${ }^{3}$ Faculty of Chemistry, Ho Chi Minh City University of Education, Ho Chi Minh City, Vietnam

${ }^{4}$ Materials Technology Key Laboratory, Vietnam National University Ho Chi Minh City, Ho Chi Minh City, Vietnam
\end{abstract}

*nguyentranha@hcmut.edu.vn

\begin{abstract}
In this research, a novel organic photocatalyst of 10-(Perylene-3-yl-10H-Phenoxazine (PHP) has been synthesized successfully from perylene and phenoxazine via Buchwald-Hartwig C-N coupling. The chemical structure of catalyst was determined via proton nuclear magnetic resonance $\left({ }^{1} \mathrm{H}-\mathrm{NMR}\right)$ spectrum and optical properties were investigated through UV-Vis spectroscopy. The PHP has been used as the reducing photoredox catalyst for organocatalyzed atom transfer radical polymerization (ATRP) under UV irradiation. The well controlled molecular weight of polymers based on methyl methacrylate monomers have been obtained with monomer conversion up to $77.61 \%$ and low polydispersity index under 1.5 .
\end{abstract}

Keywords: methacrylate monomer, phenoxazine, organic photocatalyst, atom transfer radical polymerization.

How to cite: Vo, T. H., Le, H. T., Nguyen, T. A., Ho, N. Q., Le, T. V., Tran, D. H., Truong, T. T., \& Nguyen, H. T. (2020). Synthesis of novel organocatalyzed phenoxazine for free metal atom transfer radical polymerization. Polimeros: Ciência e Tecnologia, 30(2), e2020018. https://doi.org/10.1590/0104-1428.10119.

\section{Introduction}

The polymerization for synthetic polymers according to metal catalysts by the ATRP mechanism is considered as the advanced process in the polymer industry ${ }^{[1-3]}$. The use of transition metal during synthetic procedure gives many advantages including controlled the molecular weight and polydispesity index of obtained polymer as well as controlled the end-groups of obtained polymers but the obtained polymeric products always remain the trace of transition metals ${ }^{[4,5]}$. This elimination of metals catalyst caused tremendous damage in the subsequent use of polymer products in bio-medicine, opto-electronic application. To overcome this issue, the organic photocatalyst $(\mathrm{O}-\mathrm{ATRP} / \mathrm{metal}$-free ATRP) has been developed for synthesis of the metal-free polymer via controlled radical polymerization ${ }^{[6]}$ which gradually replace the traditional ATRP-based transition metal catalysts $^{[6-8]}$. There have been many studies on the field of $O$-ATRP polymerization using organic photocatalyst $\mathrm{t}^{[7,8]}$ and light for the catalyst activation process ${ }^{[9]}$. Matyjaszewski and colleagues have used phenoloxazine and phenolthiazine as organic photocatalysts for the controlled polymerization of acrylonitrile ${ }^{[10]}$. Miyake and colleagues used organic catalysts (perylene, diaryl dihydrophenazines) for ATRP of

MMA monomer under visible light ${ }^{[11]}$. Further, Cheng and colleagues used fluorescein as an organic catalyst to control polymerization of $\mathrm{MMA}^{[12]}$. In addition, the metal-free ATRP has been applied for modification/functionalization of polymer surfaces which enhanced the reactivity of polymers ${ }^{[13]}$. It is clearly that a number of phenoxazine derivatives have been developed as visible light absorbing as organic photoredox catalysts (PCs) with excited state reduction potentials. The phenoxazine derivatives have been modified through extending the conjugation on the phenoxazine core via installation of biphenyl core substituents ${ }^{[14,15]}$. In addition, the perylene was the first organic photoredox catalysts for O-ATRP using visible light-absorbing, but it is less efficient compared to these other PC families ${ }^{[7]}$. However, the combination of phenoxazine with perylene as a photocatalyst 10-(Perylene-3-yl-10H-Phenoxazine) have not been reported which can be proposed to enhance the excited state reduction potentials of PC that would be efficient for O-ATRP process.

In this research, the novel organic photocatalyst 10-(Perylene3-yl-10H-Phenoxazine) (PHP) have been synthesized and applied for the polymerization of MMA monomer as the 
first time. The structure of PHP has been characterized via FTIR and ${ }^{1} \mathrm{H}$ NMR spectroscopy. In addition, the optical properties of PHP catalyst have been evaluated via UV-Vis spectroscopy. We also investigated the efficiency of PHP organic photocatalyst for $O$-ATRP process of MMA monomer.

\section{Materials and Methods}

\subsection{Materials}

Perylene (99\%), Phenoxazine (99\%), Pd(OAc) 2 (99\%) were purchased by Sigma Aldrich. NBS (99\%), P(t-Bu) ${ }_{3}(98 \%)$, NaOt-Bu (97\%), MMA (99\%) were purchased by Merck. Phenyl 2-bromo-2-methylpropanoate $\left(\mathrm{C}_{10} \mathrm{H}_{11} \mathrm{BrO}_{2}\right)$ was synthesized at our lab. All the solvents were purchased from Fisher Chemicals.

\subsection{Characterization}

${ }^{1} \mathrm{H}-\mathrm{NMR}$ spectra were recorded in deuterated chloroform $\left(\mathrm{CDCl}_{3}\right)$ with tetramethylsilane as an internal reference, on a Bruker Avance $500 \mathrm{MHz}$. UV-vis spectrum of polymer samples was recorded at the key laboratory, Department of Materials Technology - Ho Chi Minh City University of Technology, on Shimadzu UV-Vis 2450 of Shimadzu Sciencetific at room temperature $\left(25^{\circ} \mathrm{C}\right)$ with a range of $300 \mathrm{~nm}$ to $800 \mathrm{~nm}$, scanning speed of $200 \mathrm{~nm} / \mathrm{min}$. The spectra of GPC were recorded at the key laboratory, Department of Materials Technology - Ho Chi Minh City University of Technology, on Polymer PL-GPC 50.

\subsection{Synthesis of 1-Bromoperylene}

Perylene (600 mg, $2.378 \mathrm{mmol}$ ) and $10 \mathrm{ml}$ anhydrous DMF were added into $50 \mathrm{ml}$ two - necked flask at $0{ }^{\circ} \mathrm{C}$. Aluminum foil was thoroughly wrapped around to cover the reaction vial, blocking out light. In the dark, $N$-bromosuccinimide (NBS) (423.25 mg, $2.378 \mathrm{mmol}$ ) in $5 \mathrm{ml}$ anhydrous DMF was slowly added to this solution using dropping funnel, and stirred for $4 \mathrm{~h}$ at $0^{\circ} \mathrm{C}$ and $20 \mathrm{~h}$ at room temperature. Following, the reaction was terminated with a $2 \mathrm{M} \mathrm{HCl}$ solution, extracted with $100 \mathrm{ml} \mathrm{CHCl}_{3}$ and dried with anhydrous $\mathrm{K}_{2} \mathrm{SO}_{4}$. The product was precipitated in cold $n$-hexane and dried under vacuum to give a yellow powder (590.71 mg; 75\%).

${ }^{1} \mathrm{H}$ NMR $\left(500 \mathrm{MHz}, \mathrm{CDCl}_{3}\right), \delta(\mathrm{ppm}): 8.23(\mathrm{~d}, 1 \mathrm{H})$, $8.20(\mathrm{~d}, 1 \mathrm{H}), 8.15(\mathrm{~d}, 1 \mathrm{H}), 8.07(\mathrm{~d}, 1 \mathrm{H}), 7.99(\mathrm{~d}, 1 \mathrm{H})$, $7.76(\mathrm{~d}, 1 \mathrm{H}), 7.71(\mathrm{~d}, 2 \mathrm{H}), 7.58(\mathrm{t}, 1 \mathrm{H}), 7.49(\mathrm{t}, 2 \mathrm{H})$.

\subsection{Synthesis of 10- (Perylene-3-yl-10H-Phenoxazine (PHP)}

A literature procedure was adapted for this synthesis. A $50 \mathrm{ml}$ storage flask was charged with magnetic stir bar, flamed under vacuum and back-filled with nitrogen three times. The flask was then charged with phenoxazine (183.21 mg), NaOtBu (144.15 mg), Pd(OAc), catalyst (4.49 mg), $\mathrm{P}(\mathrm{tBu})_{3}(8.09 \mathrm{mg})$ and dry toluene $(45 \mathrm{ml})$. The flask was evacuated and back-filled three times with nitrogen before 3-bromoperylene (331.21 mg) was added. The flask was then placed in an oil bath at $110{ }^{\circ} \mathrm{C}$ under while stirring for 24 hours. The flask was then cooled to room temperature and solution was diluted with $\mathrm{CHCl}_{3}$, washed with water, brine, dried with $\mathrm{K}_{2} \mathrm{CO}_{3}$ and purified using column chromatography (3.3\% EtOAc/hexane). The product was dried under reduced pressure to yield $78 \%$ of a red orange solid.

${ }^{1} \mathrm{HNMR}\left(500 \mathrm{MHz}, \mathrm{CDCl}_{3}\right), \delta(\mathrm{ppm}): 8.34-7.48(\mathrm{~m}, 11 \mathrm{H})$, $6.73(\mathrm{~d}, 2 \mathrm{H}), 6.64(\mathrm{t}, 2 \mathrm{H}), 6.53(\mathrm{t}, 2 \mathrm{H}), 5.89(\mathrm{~d}, 2 \mathrm{H})$.

\subsection{Synthesis of initiator of phenyl 2-bromo-2- methylpropanoate (PhBMP-initiator).}

A $50 \mathrm{ml}$ storage flask was charged with magnetic stir bar, flamed under vacuum and back-filled with nitrogen three times. $10 \mathrm{mg}(0.106 \mathrm{mmol})$ of phenol was added to anhydrous THF $(10 \mathrm{ml})$ at $0{ }^{\circ} \mathrm{C}$ under nitrogen. Then, $21.45 \mathrm{mg}(0.116 \mathrm{mmol})$ of 2-bromo-2-methylpropanoyl chloride in $10 \mathrm{ml}$ of THF was dropwise added to the mixture reaction at $0{ }^{\circ} \mathrm{C}$. The mixture was continuously stirred at room temperature for $4 \mathrm{~h}$. After completion of the reaction, $10 \mathrm{~mL}$ of distilled water was added to the reaction mixture, which was extracted with dichloromethane. The organic layer was washed with $10 \%$ solution of $\mathrm{Na}_{2} \mathrm{~S}_{2} \mathrm{O}_{3}$ and $10 \%$ solution of $\mathrm{KOH}$, dried over anhydrous $\mathrm{K}_{2} \mathrm{CO}_{3}$. The product was purified via column chromatography using eluent of EtOAc/hexane (50/50) to obtained the pure product of phenyl 2-bromo-2-methylpropanoate as colorless liquid (Yield: 97\%, $\mathrm{R}_{\mathrm{f}}=0.7$ ).

${ }^{1} \mathrm{H}$ NMR (500 MHz, $\left.\mathrm{CDCl}_{3}\right), \delta(\mathrm{ppm}): 7.31(\mathrm{t}, 3 \mathrm{H})$, $7.520(\mathrm{~d}, 2 \mathrm{H}), 1.98(\mathrm{~d}, 6 \mathrm{H})$.

\subsection{Measure UV-vis of PHP and Perylene at different concentrations}

10-(Perylene-3-yl-10H-Phenoxazine (PHP) and perylene were analyzed by UV-vis to compare the spectral absorption in soluble form in THF solvent. Perylene and PHP were dissolved in THF at different concentrations of 50, 40, 30, 20, $10(\mu \mathrm{M})$ as measured by Shimadzu UV-Vis 2450 at room temperature range of $200 \mathrm{~nm}$ to $800 \mathrm{~nm}, 50 \mathrm{~nm} / \mathrm{min}$.

\subsection{General Synthesis of Polymers}

PMMA was synthesized via UV light-induced metal-free ATRP using the PhBMP-initiator and PHP as organic photocatalyst. In a typical experiment, $11.43 \mathrm{mg}(47 \mu \mathrm{mol})$ of PhBMP initiator was placed in a $25 \mathrm{~mL}$ flask, to the solution $1 \mathrm{~mL}$ of degassed THF was added by a syringe. The solution was stirred until it became homogeneous solution. Then, MMA monomer $(0.5 \mathrm{~mL}, 4.7 \mathrm{mmol})$ and PHP $(2.1 \mathrm{mg}, 4.7 \mu \mathrm{mol})$ was added separately. The mixture was degassed by three freeze-pump-thaw cycles. The solution was continuously stirred until it became homogeneous and placed in a UV-box (wavelength of $365 \mathrm{~nm}$ ) for $24 \mathrm{~h}$ at room temperature. Finally, the resulted polymer solution was precipitated in cold methanol, followed drying under vacuum to give the desired product.

\section{Results and Discussion}

The synthesis of organic photocatalyst 10- (Perylene3-yl-10H-Phenoxazine (PHP) was illustrated in Scheme 1. 1-bromo perylene was synthesized through bromination of electrophilic substitution using NBS in DMF, and the yield of reaction was obtained as $95 \%$. Then 1-bromo pyrelene was reacted with phenothiazine via Buchwald-Hartwig 
$\mathrm{C}-\mathrm{N}$ coupling in the presence of $\mathrm{Pd}(\mathrm{OAc})_{2}$ and $\mathrm{P}(\mathrm{t}-\mathrm{Bu})_{3}$ as catalyst and ligand, respectively (Yield: 78\%).

The chemical structure of PHP was analyzed via ${ }^{1} \mathrm{H} N \mathrm{NR}$ spectrum in Figure 1. The data showed that ${ }^{1} \mathrm{H}$ NMR spectrum of PHP exhibited fully characteristic peaks of PHP including peaks of phenoloxazine and perylene. The peaks from $7.48 \mathrm{ppm}$ to $8.34 \mathrm{ppm}$ are corresponding to the protons of perylene. The peaks from $5.89 \mathrm{ppm}$ to $6.73 \mathrm{ppm}$ which assigned to the protons of phenoloxazine ring. Based on the characteristics peaks are reasonable their integration, the obtained product has been concluded that PHP catalyst was synthesized successfully.

Based on the UV-vis spectrum of PHP catalyst (Figure 2), we recognized that that the PHP absorbs the wavelength from $200-500 \mathrm{~nm}$ while the pyrene absorbs the wavelength from $200-450 \mathrm{~nm}$. The UV-vis spectrum of 10-(Perylene-3-yl-10H-Phenoxazine (PHP) curves exhibited two distinct absorption peaks at 250 and $450 \mathrm{~nm}$ which corresponding to the absorption of phenoxazine and pyrene moieties, respectively. Moreover, the spectra showed a linear correlation between concentration and absorbance, and the molar extinction coefficient was determined through the Lambert - Beer law. In addition, the PHP exhibited the high intensity light absorption at wavelength $\lambda_{\max }=441 \mathrm{~nm}, \lambda_{\max 2}=417 \mathrm{~nm}$ with coefficient is $\varepsilon_{1}=40870\left(\mathrm{M}^{-1} \cdot \mathrm{cm}^{-1}\right), \varepsilon_{2}=36980\left(\mathrm{M}^{-1} \cdot \mathrm{cm}^{-1}\right)$. This results confirmed that 10-(Perylene-3-yl-10H-Phenoxazine (PHP) catalyst can be activated in visible light (violet/blue light).

To see more clearly, we consider the same concentration of perylene precursor and PHP at $50 \mu \mathrm{M}$ (Figure 3)

The spectrum showed that PHP has higher absorbance than perylene in the same range of wavelength. For example, at a wavelength of $\lambda=440 \mathrm{~nm}$, the absorbance of perylene was 0.536 while PHP was 2.093 . This result suggested that the high absorption intensity of PHP is higher than those of

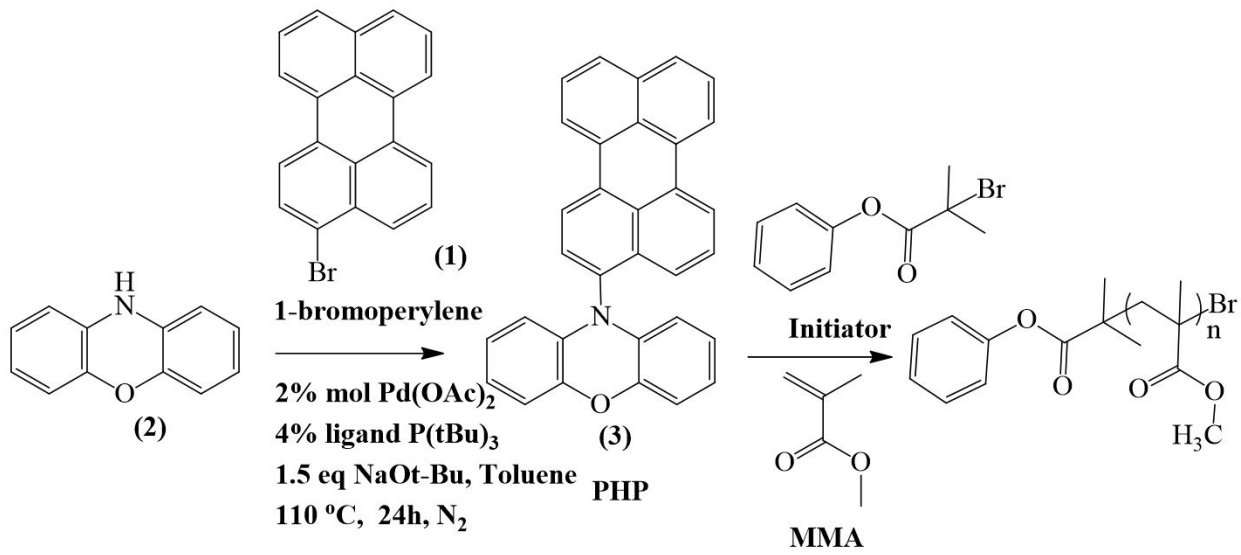

Scheme 1. Synthesis of PHP organic photocatalyst and general O-ATPP of methyl mathacrylate monomer.

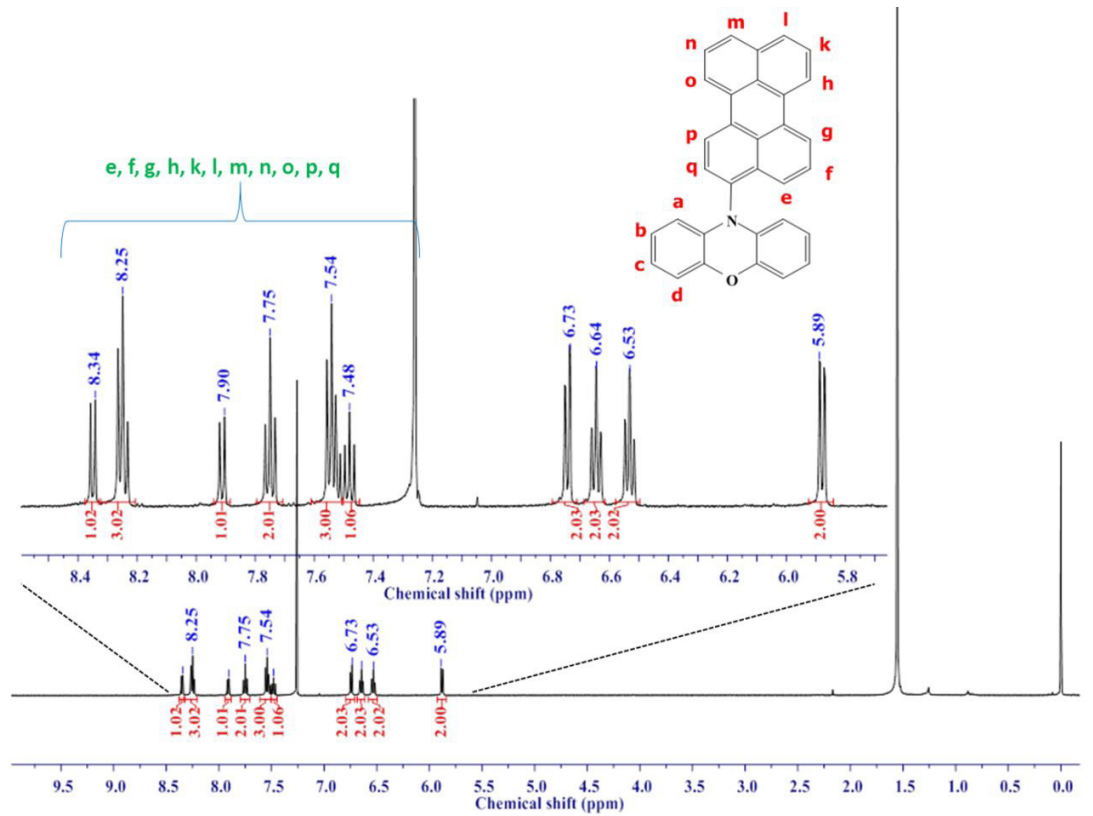

Figure 1. ${ }^{1} \mathrm{H}$ NMR of 10-(Perylene-3-yl-10H-Phenoxazine (PHP) catalyst. 


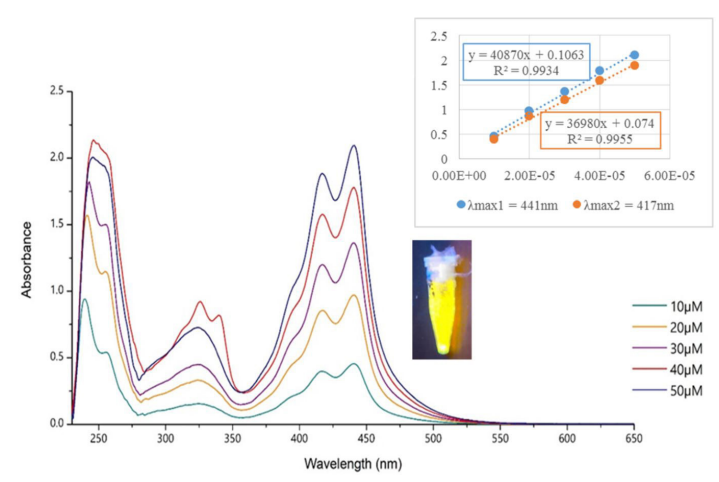

Figure 2. UV-Vis spectrum of 10-(Perylene-3-yl-10H-Phenoxazine (PHP).

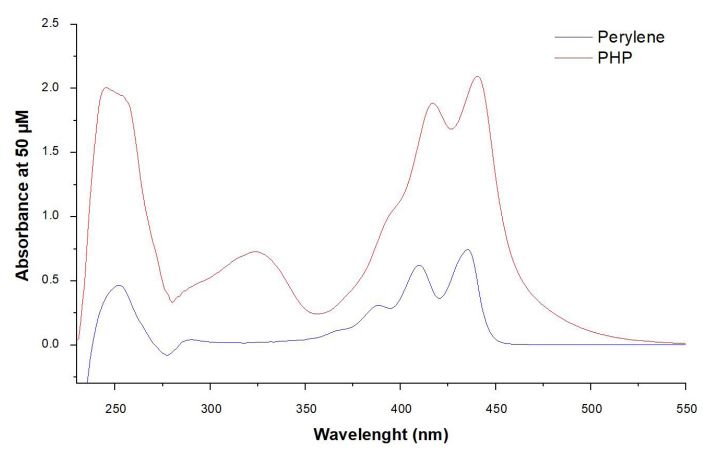

Figure 3. UV-Vis spectrum of PHP and Perylene at $50 \mu \mathrm{M}$

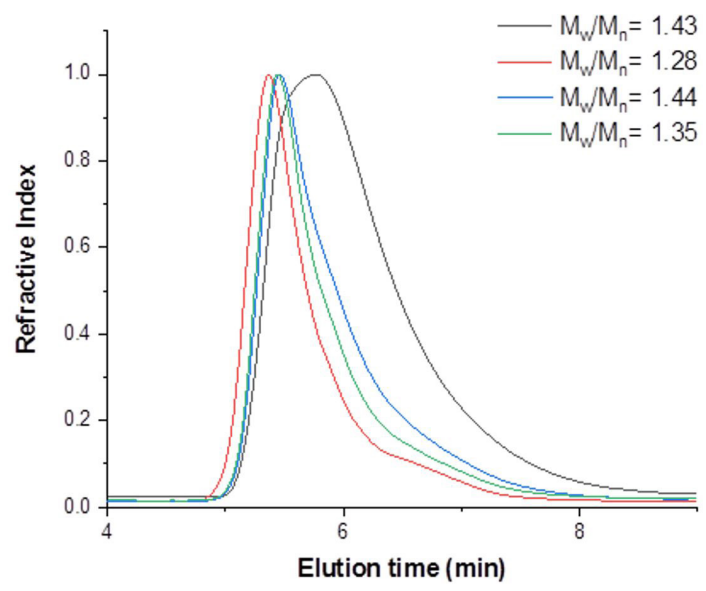

Figure 4. GPC of obtained PMMA.

Table 1. Macromolecular Characteristic Features of PMMA Synthesized by O-ATRP Using PHP Catalyst.

\begin{tabular}{lcccc}
\hline & & & & \\
& & & & \\
{$[100]:[1]:[0.5]$} & 62.69 & 21670 & 31160 & 1.44 \\
{$[100]:[1]:[0.1]$} & 60 & 17970 & 25742 & 1.43 \\
{$[100]:[1]:[0.02]$} & 77.61 & 30450 & 38880 & 1.28 \\
\hline & 56.42 & 24910 & 33677 & 1.35 \\
\hline
\end{tabular}

perylene that lead to the activation efficiency for organic photocatalyst polymerization.

According to the pioneer work of Hawker ${ }^{[16]}$, Matyjaszewski $^{[5,13]}$, and Miyake ${ }^{[8,17]}$, we carried out the following process for metal-free ATRP where PHP is used as the organic photocatalyst. Under UV irradiation, PHP is excited to form a reductant PHP*, which activates phenyl 2-bromo-2-methylpropanoate (PBMP) initiator and generates radicals. The generated radical can be added to methyl methacrylate monomers (MMA) to form alkyl radicals which are deactivated by the oxidized radical cation PHP* to regenerate the ground state of PHP. In this typical O-ATRP, we also investigated the solvents, the molar ratio of PHP catalyst with initiator, monomers which impact to the efficiency of polymerization.

The polymerization process is performed in the presence of the PHP catalyst following the O-ATRP procedure. The content of catalyst at $0.5 ; 0.1 ; 0.05 ; 0.02$ equivalent has been investigated for polymerization of methyl methacrylate. The reactions were carried out in THF solvent under UV irradiation of $365 \mathrm{~nm}, 24$ hours. The results of O-ATRP for MMA polymerization using PHP catalyst are presented in the following Table 1.

The result showed that the amount of PHP about 5\% molar ratio comparing with initiator give the high monomer conversion of $77.61 \%$ for $24 \mathrm{~h}$. On the other hand, the conversion of monomer in the polymerization was decreased if the amount of PHP catalyst decreased. It should be noted that the resulted PMMA exhibited the $\mathrm{M}_{\mathrm{n}}$ of $30.450 \mathrm{~g} / \mathrm{mol}$ which is with the polydispersity index (Đ) of obtained PMMA exhibited the value of 1.28 which is reasonable for controlled polymerization (normally $Đ$ is required below 1.5) (Figure 4).

\section{Conclusion}

10-(perylen-yl)-10H-phenoxazine (PHP) has been synthesized based on phenoxazine and pyrene has been proved to be an efficient metal-free catalyst for O-ATRP which produced polymethacrylates with controlled molecular weight of $30.457 \mathrm{~g} / \mathrm{mol}$ as well as narrow polydispersity of 1.28 by UV irradiation. This research enables the synthesis procedure for potential bio/electronic polymeric materials which will eliminate the trace metal element in final polymeric compound.

\section{Acknowledgement}

This research is funded by Vietnam National University Ho Chi Minh City (VNU-HCM) under grant number NV2019-20-03.

\section{References}

1. Zetterlund, P. B., Kagawa, Y., \& Okubo, M. (2008). Controlled/ Living radical polymerization in dispersed systems. Chemical Reviews, 108(9), 3747-3794. http://dx.doi.org/10.1021/ cr800242x. PMid:18729519.

2. Moad, G., Rizzardo, E., \& Thang, S. H. (2008). Radical additionfragmentation chemistry in polymer synthesis. Polymer, 49(5), 1079-1131. http://dx.doi.org/10.1016/j.polymer.2007.11.020. 
3. Keddie, D. J., Carlos, G. S., Moad, G., Rizzardo, E., \& Thang, S. H. (2011). Switchable Reversible Addition-Fragmentation Chain Transfer (RAFT) polymerization in aqueous solution, $\mathrm{N}$, N-Dimethylacrylamide. Macromolecules, 44(17), 6738-6745. http://dx.doi.org/10.1021/ma200760q.

4. Matyjaszewski, K., \& Xia, J. (2001). Atom transfer radical Polymerization. Chemical Reviews, 101(9), 2921-2990. http:// dx.doi.org/10.1021/cr940534g. PMid:11749397.

5. Matyjaszewski, K. (2012). Atom Transfer Radical Polymerization (ATRP): Current status and future perspectives. Macromolecules, 45(10), 4015-4039. http://dx.doi.org/10.1021/ma3001719.

6. Shanmugam, S., Xu, J., \& Boyer, C. (2017). Photocontrolled living polymerization systems with reversible deactivations through electron and energy transfer. Macromolecular Rapid Communications, 38(13), 1700143. http://dx.doi.org/10.1002/ marc.201700143. PMid:28556363.

7. Miyake, G. M., \& Theriot, J. C. (2014). Perylene as an organic photocatalyst for the radical polymerization of functionalized vinyl monomers through oxidative quenching with alkyl bromides and visible light. Macromolecules, 47(23), 82558261. http://dx.doi.org/10.1021/ma502044f.

8. Theriot, J. C., Lim, C. H., Yang, H., Ryan, M. D., Musgrave, C. B., \& Miyake, G. M. (2016). Organocatalyzed atom transfer radical polymerization driven by visible light. Science, 352(6289), 1082-1086. http://dx.doi.org/10.1126/science. aaf3935. PMid:27033549.

9. Corrigan, N., Yeow, J., Judzewitsch, P., Xu, J., \& Boyer, C. (2019). Seeing the light: advancing materials chemistry through Photopolymerization. Angewandte Chemie International Edition, 58(16), 5170-5189. http://dx.doi.org/10.1002/anie.201805473. PMid:30066456.

10. Pintauer, T., Zhou, P., \& Matyjaszewski, K. (2002). General method for determination of the activation, deactivation, and initiation rate constants in transition metal-catalyzed atom transfer radical processes. Journal of the American Chemical Society, 124(28), 8196-8197. http://dx.doi.org/10.1021/ ja0265097. PMid:12105893.

11. Dadashi-Silab, S., Pan, X., \& Matyjaszewski, K. (2017). Phenyl Benzo [b] Phenothiazine as a visible light Photoredox Catalyst for metal-free atom transfer radical Polymerization. Chemistry (Weinheim an der Bergstrasse, Germany), 23(25), 5972-5977. http://dx.doi.org/10.1002/chem.201605574. PMid:28009492.

12. Corrigan, N., Shanmugam, S., Xu, J., \& Boyer, C. (2016). Photocatalysis in organic and polymer synthesis. Chemical Society Reviews, 45(22), 6165-6212. http://dx.doi.org/10.1039/ C6CS00185H. PMid:27819094.

13. Matyjaszewski, K., \& Tsarevsky, N. V. (2014). Macromolecular engineering by atom transfer radical polymerization. Journal of the American Chemical Society, 136(18), 6513-6533. http:// dx.doi.org/10.1021/ja408069v. PMid:24758377.

14. McCarthy, B., \& Miyake, G. M. (2018). Organocatalyzed atom transfer radical polymerization catalyzed by core modified N-Aryl Phenoxazines Performed under Air. ACS Macro Letters, 7(8), 1016-1021. http://dx.doi.org/10.1021/ acsmacrolett.8b00497. PMid:31827976.

15. McCarthy, B. G., Pearson, R. M., Lim, C. H., Sartor, S. M., Damrauer, N. H., \& Miyake, G. M. (2017). StructureProperty relationships for Tailoring Phenoxazines as reducing Photoredox Catalysts. Journal of the American Chemical Society, 140(15), 5088-5101. http://dx.doi.org/10.1021/jacs.7b12074. PMid:29513533.

16. Treat, N. J., Sprafke, H., Kramer, J. W., Clark, P. G., Barton, B. E., Read de Alaniz, J., Fors, B. P., \& Hawker, C. J. (2014). Metal-free atom transfer radical Polymerization. Journal of the American Chemical Society, 136(45), 16096-16101. http:// dx.doi.org/10.1021/ja510389m. PMid:25360628.

17. Pearson, R. M., Lim, C. H., McCarthy, B. G., Musgrave, C. B., \& Miyake, G. M. (2016). Organocatalyzed atom transfer radical polymerization using N-Aryl Phenoxazines as Photoredox Catalysts. Journal of the American Chemical Society, 138(35), 11399-11407. http://dx.doi.org/10.1021/ jacs.6b08068. PMid:27554292.

Received: Feb. 09, 2020

Revised: June 21, 2020

Accepted: June 22, 2020 